\title{
O PROJETO DE UM BRAÇO HIDRÁULICO COMO FERRAMENTA DE APRENDIZAGEM ATIVA
}

\author{
GLAUCIO LUCIANO ARAÚJO ${ }^{1}$, ANDRÉIA ALMEIDA MENDES ${ }^{2}$, \\ FERNANDA COTA TRINDADE ${ }^{3}$, LUCIANA ROCHA CARDOSO ${ }^{4}$.
}

\begin{abstract}
1 Doutor em Engenharia Agrícola pela Universidade Federal de Viçosa UFV, coordenador e professor no Centro Universitário UNIFACIG. glaucio.araujo@sempre.facig.edu.br .

2 Doutora em Linguística pela Universidade Federal de Minas Gerais (UFMG), Coordenadora de Pesquisa e Extensão e professora do Centro Univeristário UNIFACIG. andreialetras@ yahoo.com.br 3 Mestre em Arquitetura e Urbanismo pela Universidade Federal do Espírito Santo, coordenadora e professora no Centro Universitário UNIFACIG. fercotat@gmail.com.

4 Mestre em Ciência da Computação pela Universidade Federal de Viçosa (UFV) ), professora no Centro Universitário UNIFACIG. luroca@gmail.com.
\end{abstract}

\section{RESUMO}

A metodologia de projetos como ferramenta de aprendizagem ativa não pode ser tida como novidade, uma vez que já é utilizada a algum tempo em salas de aula por todo o planeta; no entanto, ela ainda pode ser considerada como atual e, em algumas instituições de ensino, ela é tratada como uma metodologia inovadora, pois as aulas ainda seguem o protocolo tradicional. $\mathrm{O}$ objetivo desta pesquisa foi relatar a experiência da aplicação da metodologia de projetos, em um semestre da disciplina de "Fenômenos de Transporte", no curso de Engenharia de Produção do Centro Universitário UNIFACIG, no qual, por meio do projeto de um braço hidráulico, os alunos puderam aprender na prática princípios de mecânica e estática dos fluidos, como o princípio de Pascal. Além do relato do professor, também foram coletados depoimentos de alunos sobre suas experiências como a metodologia de ensino. Frente aos resultados a metodologia pode ser considerada exitosa e viável para o ensino da disciplina de "Fenômenos de Transporte", pois os alunos se mantiveram engajados e motivados durante o processo.

Palavras-chave: Metodologia de Projetos; Mecânica dos Fluidos; Braço Hidráulico.

\section{THE PROJECT OF A HYDRAULIC ARM AS AN ACTIVE LEARNING TOOL}

\begin{abstract}
The methodology of projects as an active learning tool cannot be considered novelty, it has been used for some time in classrooms all over the planet, however it can still be considered as current, and in some educational institutions it is treated as an innovative methodology, because the classes still follow the traditional protocol. The objective of this research was to report the experience of applying the project methodology, in a semester of the discipline of "Fenômenos de Transporte", in the course of Production
\end{abstract}


Engineering of UNIFACIG University Center, where by means of the design of a hydraulic arm, the students were able to learn in practice principles of mechanics and static of fluids, as the Pascal principle. In addition to the teacher's report, we also collected testimonials from students about their experiences as teaching methodology. In view of the results, the methodology can be considered successful and feasible for the teaching of the discipline of "Fenômenos de Transporte", because the students remained engaged and motivated during the process.

Keywords: Project Methodology; Mechanics of Fluids; Hydraulic Arm.

\section{INTRODUÇÃO}

Muito se discute a respeito do papel do professor no processo de aprendizagem do aluno e a função social que a instituição de ensino também possui neste processo. $O$ discurso pedagógico vem permeado de conceitos ligados à aprendizagem ativa, tais como: sentido, significado da aprendizagem, problemas reais, conhecimento prévio do aluno, motivação, habilidades e competências, dentre outros, com o intuito de nos fazer refletir sobre os processos de aprendizagem e as práticas utilizadas pelos professores em sala de aula.

Em função disso, devemos estar sempre atentos à nossa postura pedagógica e sobre as técnicas de ensino que são mais significativas e proporcionam maior aprendizagem aos alunos. Aulas tradicionais, com a fragmentação dos conteúdos, não são mais bem vistas no atual cenário educacional uma vez que a geração de alunos que temos hoje vive em um mundo globalizado e altamente tecnológico, não "aceitando" a passividade antes proposta pelas instituições de ensino.

Há mais de um século, Dewey (1907) alerta que a educação não pode ser vista como uma preparação para a vida futura, mas sim um processo de vida que represente a vida presente do aluno e que seja tão real e tão vital como o mundo em que se vive. É com este intuito de ressignificar a educação e, consequentemente, o processo de aprendizagem para que se torne mais significativo que se optou por trabalhar com a metodologia de projetos, por se acreditar que essa metodologia contribua de forma efetiva na formação integral dos alunos e consegue atrelar a teoria à prática.

Assim, este artigo objetiva relatar a experiência da aplicação da metodologia de projetos em um semestre da disciplina de "Fenômenos de Transporte", momento em que os alunos foram orientados a projetar e executar um braço hidráulico. 


\section{REFERENCIAL TEÓRICO}

Segundo Hernandez $(1998 ;$ 2000), o trabalho com projetos representa a ruptura com uma visão tradicional de educação, sendo, portanto, uma nova postura pedagógica que responde alguns desafios da sociedade ao propor uma nova maneira de se compreender e vivenciar a educação; o aprendizado deixa de ter por base a simples memorização e se apoia no processo de conhecer e intervir no real.

Ao adotar essa nova postura de trabalho, o professor estimula o aluno a aprender participando, a vivenciar sentimentos, a tomar atitudes diante de problemas, a escolher procedimentos para atingir aos objetivos que se tem em vista. Assim, quando um aluno participa de um projeto, ele passa por um processo de construção de conhecimento que está integrado às práticas vividas; práticas essas que proporcionarão aprendizado a partir das experiências que lhe foram proporcionadas, pelos problemas que foram criados durante a execução do projeto e pelas ações desencadeadas (JOLIBERTet al., 1994).

Ainda segundo esses autores, o projeto é considerado uma nova proposta pedagógica que traz inovação ao processo de aprendizado ao se tentar resolver situações-problema, uma vez que gera situações reais e diversificadas de aprendizado que tornam os alunos sujeitos culturais, uma vez que possibilitam a eles a fazerem parte do processo de decisão, opinião, debate e construção da autonomia e compromisso.

Algumas características são consideradas fundamentais no trabalho com projetos:

1) Um projeto é uma atividade intencional: o envolvimento dos alunos é uma característica do trabalho de projetos, o que pressupõe um objetivo que dá unidade e sentido às várias atividades, bem como um produto final que pode assumir formas muito variadas, mas procura responder ao trabalho.

2) Num projeto, a responsabilidade e a autonomia dos alunos são essenciais: os alunos são co-responsáveis pelo trabalho e pelas escolhas ao longo do desenvolvimento do projeto. Em geral, fazem-nos em equipe, motivo pelo qual a cooperação está também quase sempre relacionada ao trabalho.

3) A autenticidade é uma característica fundamental de um projeto: o problema a resolver é relevante e tem um caráter real para os alunos. Não se trata de mera reprodução de conteúdos prontos. Além disso, não é independente do contexto sociocultural, e os alunos procuram construir respostas pessoais e originais.

4) Um projeto envolve complexidade e resolução de problemas: o objetivo central do projeto constitui um problema ou uma fonte geradora de problemas que exige uma atividade para sua resolução. 
5) Um projeto percorre várias fases: escolha do objetivo central, formulação dos problemas, planejamento, execução, avaliação, e divulgação dos trabalhos (ABRANCHES, 1995, p. 62).

A análise dessas características confirma que o trabalho de projetos vai além da visão tradicional de educação e se insere em um processo global e complexo de aprendizagem ativa em que conhecer o real e intervir nesse real são atividades interligadas.

Segundo Leite (1996), ao se adotar a utilização de projetos como prática pedagógica, deve-se ter em mente a concepção de conhecimento que se quer trabalhar para que não haja problemas em relacionar a teoria com a prática. Segundo a autora, o projeto não pode ser trabalhado dentro da concepção espontaneísta de educação, pois, ao negar e desvalorizar os conteúdos disciplinares, fragmenta-se o processo educacional. Em função disso, o projeto deve ser desenvolvido com base em uma concepção integradora que abarque tanto o processo de aprendizagem dos conteúdos trazidos pelas disciplinas como também a participação dos alunos e sua interação com a realidade cultural, através de um processo global e complexo de inter-relação.

A concepção integradora de educação traz mudanças significativas no processo de aprendizagem, permitindo aos alunos que analisem os problemas, as situações e também os acontecimentos dentro de um contexto globalizante que utilize tanto os conhecimentos disciplinares como também a experiência sociocultural dos alunos. $\mathrm{O}$ diferencial dessa concepção com relação a uma concepção cientificista conservadora é que os alunos não aprendem os conteúdos das disciplinas de forma teórica e a partir de conceitos abstratos; os conteúdos se tornam, de forma crítica e dinâmica, o meio pelo qual se amplia a formação dos alunos e sua interação com a realidade; assim, os conteúdos disciplinares ganham significados diversos a partir das experiências dos alunos com o projeto (LEITE, 1996).

Para que esse processo tenha êxito, o papel do professor é essencial; ele deve coordenar, informar e intervir no projeto à medida em que o trabalho avança, além de saber incentivar e esperar os momentos certos para essa intervenção, trabalhando atividades coletivas, mas que respeitem a individualidade dos alunos e os façam desenvolver sua autonomia, criatividade e também a sua socialização, através de um planejamento flexível e coletivo (LEGRAND, 1993). 
Deve-se atentar, portanto, ao se trabalhar com projetos, a uma mudança de paradigmas na perspectiva tradicional de educação, que vê "o processo de ensinar e aprender fragmentado, disciplinar, descontextualizado, unilateral, direcionador que se constata na maioria das escolas" (GIROTTO, 2002-2003, p.88), mudança essa que deve pautar em uma nova perspectiva, na qual o processo educativo "tem enfoque globalizante, centrado na resolução de problemas significativos, que tem o conhecimento como instrumento para compreensão e possível intervenção na realidade" (LEITE, 1996, p. 28).

\section{MÉTODOS E TÉCNICAS}

Trata-se de um artigo de relato de experiência que objetiva realizar um estudo descritivo, de abordagem qualitativa, sobre um projeto realizado na disciplina de "Fenômenos de Transporte", do quinto período do curso de Engenharia de Produção do Centro Universitário UNIFACIG, situado na cidade de Manhuaçu - MG, com o intuito de verificar não só a eficiência da metodologia como também o comportamento, as atitudes e as habilidades/competências adquiridas pelos discentes frente a aplicação dessa metodologia ativa de aprendizagem.

\section{RESULTADOS}

A disciplina de "Fenômenos de Transporte" do curso de Engenharia de Produção apresenta uma ementa abrangente sendo trabalhados os seguintes conteúdos: Conceituação da disciplina fenômenos de transporte; Introdução à mecânica dos fluidos; Estática dos fluidos; Introdução aos fluidos em movimento; As formas integrais das leis fundamentais; Análise dimensional e semelhança; Escoamentos internos; Escoamentos externos; Introdução à transmissão de calor; Condução; Convecção; Radiação; Introdução à transferência de massa.

No projeto do braço hidráulico proposto aos alunos, eles tiveram de utilizar conceitos de três conteúdos específicos da disciplina, sendo eles: introdução à mecânica dos fluidos, estática dos fluidos e introdução aos fluidos em movimento. Os demais conteúdos da disciplina foram trabalhados por meio de outras metodologias ativas de ensino e aprendizagem. 
Durante o período letivo, os alunos tiveram encontros semanais para planejamento e execução de seus projetos, totalizando 17 encontros ao longo do semestre. Estes encontros ocorriam no laboratório de projetos e modelagem, durante o horário da disciplina e tinham duração máxima de 50 minutos. Durante os encontros, os alunos planejavam e executavam processos no intuito de atender o objetivo final do projeto.

No primeiro encontro, o professor dividiu a turma em quatro equipes de seis alunos, o processo se deu de forma totalmente aleatória, fazendo uso de um sorteio. Esse processo visava aproximar os alunos de seu futuro profissional, momento em que eles, na maioria das vezes, não terão a chance de selecionar suas equipes de trabalho; dessa forma, ao utilizar o processo de escolhas de equipe de forma aleatória, os alunos estariam aprendendo a lidar com diferenças no ambiente de trabalho. Esse intuito foi esclarecido aos alunos no momento do sorteio. Nem todos ficaram felizes com suas equipes, mas entenderam a proposta do professor.

Ainda no primeiro encontro, foram apresentadas as regras do projeto, assim como foram discutidos seus objetivos de aprendizagem. Foram mencionados os conteúdos que se pretendia trabalhar, assim como as habilidades a serem desenvolvidas. Os alunos foram informados que não existiam restrições para a quantidade e a qualidade dos materiais utilizados na execução do projeto, mas foi pedido que refletissem quanto à sustentabilidade do processo. Como já citado em Abranches (1995), ao se trabalhar com os alunos a respeito dos objetivos do projeto, cria-se uma unidade e sentido às atividades, sendo esse um dos pontos fundamentais ao se trabalhar com projetos.

Foram solicitadas aos alunos duas entregas de produtos ao longo do processo: a primeira entrega, tratava-se de um cronograma executivo do projeto, contendo detalhes de sua execução em etapas, o cronograma executivo também deveria conter um esboço do projeto e dos cálculos. As equipes tiveram quatro encontros (Figura 1) para a elaboração do cronograma. Ao longo do processo, o cronograma executivo foi avaliado quanto à coerência de suas tarefas, prazos e divisão das atividades. Algumas equipes perderam pontos nesse quesito, pois algumas atividades foram realizadas fora do prazo, devido a atrasos internos da equipe, motivados pela falta de comprometimento de membros. 
Figura 1 - Equipes durante o planejamento do projeto.

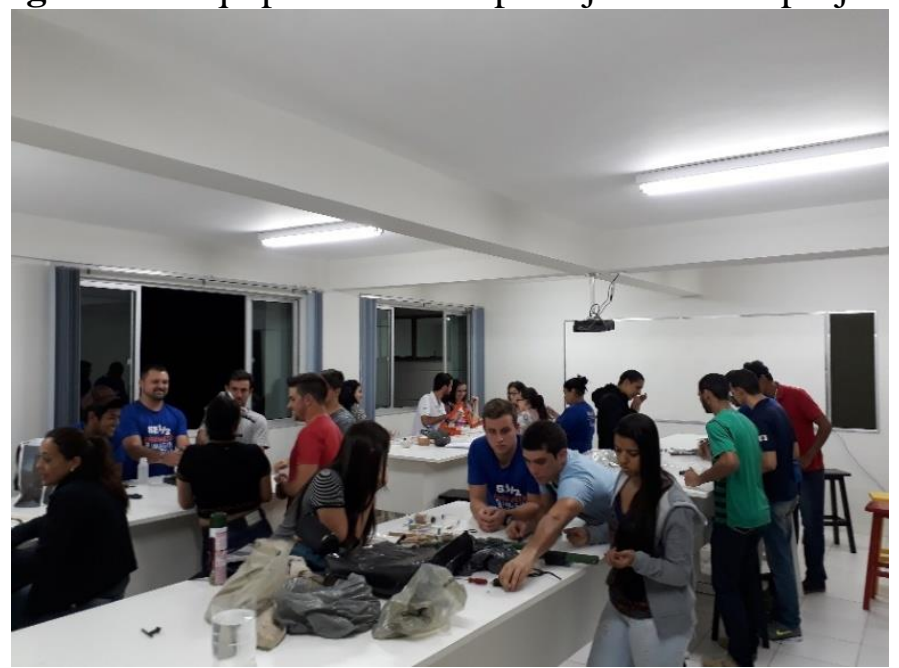

Fonte: Dados da pesquisa.

A segunda entrega tratava do braço hidráulico juntamente com um relatório final de execução do projeto com os cálculos dos princípios de mecânica dos fluidos utilizados no processo, assim como os cálculos das forças resultantes utilizando o Principio de Pascal. O braço hidráulico deveria ser entregue totalmente funcional, possibilitando a execução de uma tarefa simples, estipulada pelo professor previamente: o transporte de 3 cubos (aproximadamente 80 gramas cada, com dimensões de $7 \times 7 \times 7$ $\mathrm{cm}$ ) de uma plataforma que está no mesmo nível que a base do braço hidráulico para outra plataforma elevada em $15 \mathrm{~cm}$, distanciada, no mínimo, a $40 \mathrm{~cm}$ do local original onde estavam os cubos inicialmente (Figura 3).

A não execução da tarefa não acarretaria na perda total da nota; no entanto, poderia ser imposta uma punição referente a este quesito. Felizmente, nenhuma equipe foi penalizada, todas realizaram a tarefa simples proposta, o que demonstra que, ao longo das aulas, os alunos tiveram que desenvolver responsabilidade e autonomia, habilidades essenciais para o sucesso do trabalho em equipe (ABRANCHES, 1995).

Figura 2 - Equipes durante a execução do projeto. 


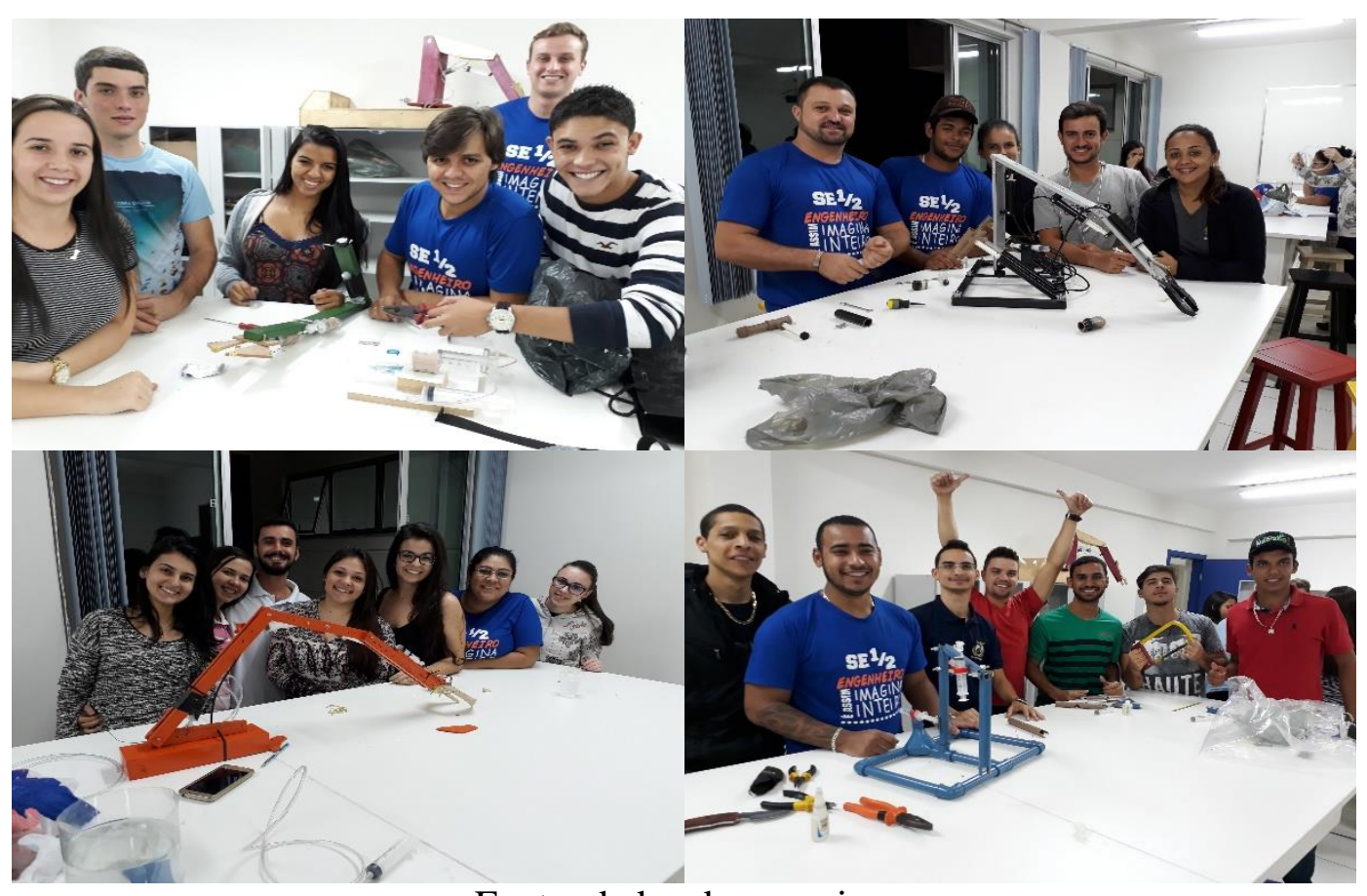

Fonte: dados da pesquisa.

Figura 3-Equipes durante a execução da tarefa proposta.

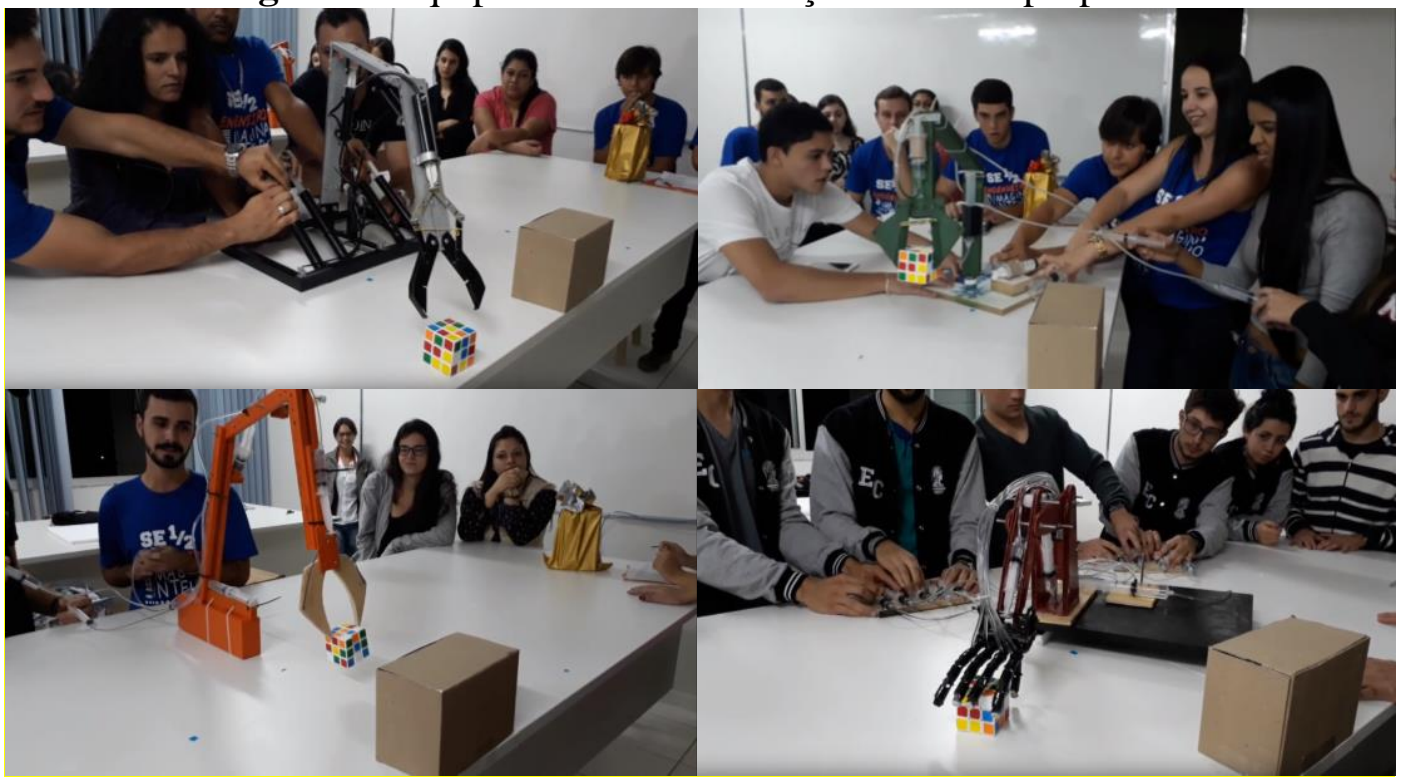

Fonte: dados da pesquisa.

Cada grupo teve de eleger um auditor interno, que foi o responsável por avaliar a execução do projeto por parte do grupo. A avaliação do auditor foi feita em cada um dos encontros de trabalho, por meio do preenchimento de um formulário disponibilizado pelo professor. Em caso de não conformidade e seriedade por parte do auditor interno, ele seria punido pelo professor com a perda de pontos, felizmente todos os auditores internos desempenharam bem o seu papel, avaliando com seriedade o seu 
grupo. A avaliação dos auditores internos se deu pelos critérios de assiduidade, comprometimento com o trabalho e proatividade na execução das tarefas.

No decorrer do semestre, os alunos trabalharam muito para alcançar seus objetivos, inicialmente eles eram motivados pelo fato da atividade fazer parte da avaliação de uma disciplina; no entanto, com o passar de alguns encontros de trabalho, esse fato deixou de ser o principal motivador do processo, pois alguns alunos perceberam que estavam aprendendo de uma forma diferente da tradicionalmente utilizada. Essa (re)significação da aprendizagem, faz com que surja uma concepção integradora de aprendizagem em contraponto com a concepção cientificista conservadora, essa nova concepção permite "aos alunos analisar os problemas, as situações e os acontecimentos dentro de um contexto e em sua globalidade, utilizando, para isso, os conhecimentos presentes nas disciplinas e sua experiência sociocultural" (LEITE, 1996, p. 4).

Houve resistência inicial em relação ao projeto, alguns alunos pensavam que seria uma atividade de ensino fundamental e não do ensino superior, como foi apresentado em um dos relatos de alunos presentes nos depoimentos abaixo. Alerta-se que, com o intuito de preservar a identidade dos participantes, seus nomes foram omitidos, passando a ser denominados por Aluno 1, 2,3 e assim por diante.

Aluno 01: "No início não achei que isso daria certo, que poderíamos aprender algo com essas atividades diferentes. Era difícil pensar como as aulas aconteciam, mas depois eu comecei a gostar, pois eu e meu grupo começamos a entender os princípios envolvidos".

Aluno 02: "Eu gostei desde o primeiro dia, achei diferente, eu estava cansada de como as aulas aconteciam, e como a disciplina tem muitas contas eu achei diferente, nós tínhamos que aplicar aquilo que pesquisávamos para fazer o braço dar certo. Nos dias do trabalho com o projeto eu não gostava de perder aula".

Aluno 03: "Quando o projeto foi proposto pelo professor, achei aquilo uma atividade de feira de ciências, daquelas que fazemos na oitava série, eu não pensava que seria tão difícil.Montar o braço foi fácil, mas calcular aquilo tudo deu bastante trabalho, tivemos de estudar muito, ver o braço funcionando e saber o como ele funcionava foi muito legal". 
Aluno 04: "Achei diferente a proposta para as aulas, eu gostei, não foi muito fácil chegar até o final, mas conseguimos. No início, alguns do meu grupo não ajudavam muito, mas quando eles começaram a perder nota e ver que eles não estavam aprendendo começaram a ajudar”.

Aluno 05: "No início, meu grupo estava um pouco perdido e o professor percebeu, ele disse que precisávamos de foco nas atividades e nos ajudou a direcionar nossas pesquisas para o projeto e dividir as tarefas, depois conseguimos fazer tudo, pois alguns começaram se dedicar mais ao projeto. Entender quais matérias da mecânica dos fluidos estavam envolvidos foi a parte mais difícil”.

Como podemos perceber nos depoimentos dos alunos, de fato ocorreu resistência inicial quanto ao projeto do braço hidráulico; mas, posteriormente, essa resistência foi quebrada. Quando os alunos perceberam que a atividade não era uma brincadeira e sim parte de uma disciplina, começaram a se empenhar mais.

Ao final do projeto, fugindo do roteiro inicial, foi proposto aos alunos uma pequena competição, em que os grupos concorreriam por um pequeno prêmio (chocolates). Foram medidos os tempos para a execução da tarefa de movimentar os cubos e a equipe com o menor tempo venceria a competição. Foi imposta uma única regra: pelo menos quatro alunos devem manejar o braço ao mesmo tempo, ficando cada comando a critério de um aluno diferente, criando um dificultador no processo. $\mathrm{O}$ impacto da atividade pode ser considerado como significativo, pois gerou um grande sentimento de empolgação nos alunos, que se divertiram com o processo de aprendizagem.

\section{CONSIDERAÇÕES FINAIS}

Ao final do projeto, foi possível observar que os sentimentos que predominavam durante o início do processo haviam mudado. Os alunos que iniciaram desconfiados e com pouca confiança no método, terminavam suas atividades confiantes e felizes, percebendo que o processo de aprendizagem havia sido significativo.

Foram observados impactos na socialização dos alunos, alguns "grupinhos" foram dissolvidos e os alunos passaram a trabalhar com outros colegas da turma, gerando mais interação entre eles e maior compartilhamento de conhecimento. Também foram percebidos reflexos positivos na frequência escolar dos alunos. 
Quanto à avaliação da aprendizagem, foi medida por meio de duas avaliações, além dos cálculos apresentados no relatório final de cada equipe. Como era de se esperar, os alunos que se empenhavam menos na execução dos projetos, identificados por meio dos auditores internos de cada grupo, tiraram notas menores em relação aos demais alunos.

De modo geral, a metodologia pode ser considerada como viável e exitosa para o ensino e aprendizagem dos conceitos de mecânica dos fluidos, da disciplina "Fenômenos de Transporte".

\section{REFERÊNCIAS}

ABRANCHES, P. Trabalho de projetos e aprendizagem matemática. In: Avaliação e Educação Matemática, RJ: MEM/USU - GEPEM, 1995.

DEWEY, John. Meu credo pedagógico. Chicago: University of Chicago Press, 1907.

GIROTTO, Cyntia Graziella Guizelim Simões. Pedagogia de Projetos: (re) significação do processo ensino-aprendizagem". Projeto de Pesquisa. Núcleo de Ensino : Faculdade de Filosofia e Ciências (UNESP- Campus de Marília). 2003. Disponível em: www.unesp.br/prograd/.../A\%2520resignificacao\%2520do\%2520ensinar.pdf. Acesso em: 16.fev.2019.

HERNÁNDEZ, Fernando. Transgressão e mudança na educação: os projetos de trabalho. Porto Alegre: Artmed, 1998.

HERNÁNDEZ, Fernando. Repensar a função da escola a partir dos projetos de trabalho: o conhecimento é um caleidoscópio. Porto Alegre: Artes Médicas, 2000.

JOLIBERT, Josette et al. Formando crianças leitoras de texto. Porto Alegre: Artes Médicas, 1994.

LEGRAND, Louis. A pedagogia do projecto. In: Trabalho de projetos: leituras comentadas. 3.ed. Portugal: Edições Afrontamento, 1993, p.36-39.

LEITE, Lúcia Helena Álvarez. Pedagogia de projetos: intervenção no presente. Presença Pedagógica, $1996 \quad$ v.2, n.8, p. 24-33, 1996. Disponível em:https://edufisescolar.files.wordpress.com/.../pedagogia-de-projetos-de-lc3baciaalvarez.pdf. Acesso em: 16 fev.2019. 